Mandates, needs, equitable resources, and current research in English language teacher education: The case of Turkey

Cepik, Saban

Zirve University, Turkey (saban.cepik@zirve.edu.tr)

Polat, Nihat $\$

Duquesne University, Pittsburgh, USA (polatn@duq.edu)

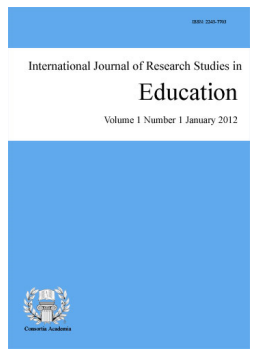

ISSN: 2243-7703 Online ISSN: 2243-7711

OPEN ACCESS

\title{
Abstract
}

Improving the quality of English language teacher education (ELTE) programs has become a major point of consideration; however, such programmatic evaluations are markedly rare. This study utilizes both numeric and interpretive qualitative data in a blended research design. The study addresses, vis-à-vis current research in related fields: What is the current situation of the Turkish ELTE programs in terms of curriculum strength and faculty resources? How do the program directors and teacher candidates envision the situation of their programs in terms of curriculum strength and faculty resources? Data included 45 ELTE curricula, interviews with 24 program directors and pre-service teachers, documents, and test scores. Findings revealed several significant associations between school type (public/private) and rank (low/high) and the number of faculty with expertise in critical areas in the field. Qualitative critical evaluations suggest both perceptual matches and mismatches between program directors and teacher candidates regarding programmatic strengths and weaknesses.

Keywords: nationwide program evaluation; teacher education; government mandates; curriculum analysis, administrators' perceptions, pre-service teachers' perceptions 


\section{Mandates, needs, equitable resources, and current research in English language teacher education: The case of Turkey}

\section{Introduction}

Preparing competent English as a foreign language (EFL) teachers has become a major point of consideration in national educational planning and policy for many countries. Indeed, access to knowledge base that potentially provides participation in the global economy makes decision-making regarding the EFL teaching enterprise a central concern (Richards, 2008). Aware of such crucial outcomes for its citizens, Turkey has recently made the teaching of EFL mandatory in primary schools. With such changes and new demands has come a dire need for a critical re-examination of where the current English language teacher education (ELTE) programs stand vis-à-vis certain domains and competencies identified in second language acquisition (SLA), curriculum studies, and second language (L2) teacher education research. Despite these new demands and current research on L2 learning and teaching, such programmatic evaluations are markedly rare. A comprehensive evaluation of these programs must take into account multiple sources of data, including current research in related fields, curricular coursework and practicum, faculty profile, and narrative accounts of program directors and teacher candidates.

This study utilizes both numeric and interpretive qualitative data in a mixed-method research design. Rather than providing an exploratory evaluation of specific ELTE programs in Turkey; using a sample of ELTE programs, it aims to explore how the curricula of such programs compare to each other and the current research in SLA and L2 teacher education. Specifically, the study addresses, vis-à-vis current research in related fields: What is the current situation of the ELTE programs in terms of curriculum strength and faculty resources? How do the program directors and teacher candidates envision the situation of their programs in terms of curriculum strength and faculty resources? Finally, we discuss possible pedagogical implications of our findings in light of current research in SLA and L2 teacher education. Hopefully, an evaluation of this sort would not only help identify curricular and pedagogical weaknesses but also suggest programmatic improvement opportunities that would facilitate more effective teacher preparation practices in Turkey, possibly with implications for other ELTE programs around the world.

\subsection{Author collaboration and positionality}

Due to the interpretive nature of qualitative data and the potential implications of the study findings for the policy and curricular situation of ELTE programs in Turkey, it seems necessary to address the nature of authors' collaboration and positionality. Author2 has previously worked as a certified teacher in two EFL contexts and one K-12 ESL (English as a second language) (USA) setting for several years and is currently working as an ESL teacher educator. Author2 also has training and experience with compiling National Council for Accreditation of Teacher Education (NCATE) program evaluation reports for ESL teacher certification. Author1 has worked as an EFL teacher in two different countries and is currently working as the director of an ELTE program in Turkey. Hence, given the research goals and the backgrounds of authors, this study does not aim to evaluate the current situation of these programs based on the current research on ESL teacher competencies because we not only acknowledge differences between the two settings but also recognize the massive amount of variation within each setting. Nor do the authors embrace a homogeneous approach to L2 teacher education that undermines the critical elements of locality and context particularities (Kumaravadivelu, 2006) that include social, political and economic and cultural realities that cannot be separated from L2 teacher education curricula and practices (Johnson, 2009).

In brief, both authors position themselves within a pedagogical framework analogous to Kumaravadivelu's (2006) cultural realism that advocates research-driven and theoretically sound L2 teacher education that 
Mandates, needs, equitable resources, and current research in English language teacher education

accounts for the contributions of proactive critical self-reflections and socio-cultural realities (Darling-Hammond \& Branson, 2005). Nonetheless, considering new goals of EFL learners in this age of technology and global mobility (Richards, 2008), both EFL and ESL teachers need to help L2 learners achieve the three TESOL (Teachers of English to the Speakers of Other Languages) goals that include ability to: communicate in social settings, succeed academically, and interact with the L2 community in socio-culturally appropriate ways (TESOL, 2010).

\section{Background of the study}

Teacher competencies - What fundamental competencies are L2 teachers required to hold? This is a hard question to address because world Englishes (Kachru, Kachru, \& Nelson, 2006) are thought in numerous countries with immensely different sociocultural, economic, political, and geographical realities. Moreover, the goals and expectations of L2 communities who reside in these countries are also very diverse (Richards, 2008). Nonetheless, despite the differences embedded within the ESL and EFL settings and the learner profiles, some competencies related to language and language learning, culture, instruction, assessment, and professional responsibilities seem to hold ground in applied linguistics and L2 teacher education research (Hinkel, 2005). This research could be categorized and presented in terms of competencies outlined in the European and American teacher education frameworks. Indeed, the European Union has recently compiled a profile that constitutes guidelines for L2 teacher education program development and evaluation. This report includes 40 competencies listed under the four domains of structure, knowledge and understanding, strategies and skills, and values (Kelly, Grenfell, Allan, Criza, \& McEvoy, 2004). Both of these frameworks are theory and research-driven comprehensive approaches in ESL teacher education with implications for ELTE; however, given the established classifications of research foci in the field of L2 teacher education (e.g., SLA, culture), the implications of these research areas for programs in the context of this study as well as authors' backgrounds and experience in the Turkish and USA contexts, TESOL's categorical framework (TESOL/NCATE, 2010) seems appropriate to serve as basis to determine to what extent current research in the field (Ellis, 2012) is informing the ELTE programs understudy.

In providing an evaluation framework for ESL teacher education in the USA, TESOL has compiled a national accreditation review manual (TESOL/NCATE, 2010) that outlines 11 standards categorized under the five domains of language and language learning, culture, instruction, assessment, and professionalism. The manual breaks down the standards into measurable competencies in rubrics that describe performance indicators to document whether or not a candidate's performance approaches, meets, or exceeds each standard. The manual provides research, theory, and application basis for each standard. Withstanding some implementation differences, most ESL teacher education programs in the USA cover competencies related to the language, culture, instruction, assessment, and professionalism domains.

The language domain includes background knowledge and skills in linguistics and first (L1) and L2 acquisition theories. Current research requires that ESL teachers be proficient in the language they teach while also demonstrate competency in basic linguistics and language systems (Andrews, 2001; Ellis, 2012) and theories about L1 and L2 acquisition (Gass \& Selinker, 2008; Hinkel, 2005; VanPatten \& Williams, 2007). Relatedly, the culture domain focuses more on the characteristics of learners (Dörnyei, 2005) and their communities and culturally responsive education (Gay, 2010), requiring teacher training about sociocultural awareness and learner variables (Horwitz, 2013; Johnson, 2009).

The instruction domain covers pedagogical competencies, including foundations of ESL curriculum, methods, learning environment, and instructional materials. In other words, competent ESL teachers implement appropriate curricula (Nation \& Macalister, 2010) and use appropriate instructional materials (Richards, 2007). Previous research also holds teachers responsible for utilizing different instructional methods (Richards \& Rodgers, 2001) with a sense of 'principled eclecticism' (Larsen-Freeman, 2003) that may not necessarily adhere to one particular method (Kumaravadivelu, 2006). Research on the assessment domain highlights competencies 
concerning the testing of learners' L2 development. Such research emphasizes competency in formative and summative assessment skills about the placement, achievement, and proficiency of L2 learners (Hughes, 2003). This research particularly underscores basic concepts and practices related to test design, development, and the selection, adaptation and development of assessment tools for different purposes (Brown, 2004; Fulcher \& Davidson, 2006).

Current research places the last domain at the heart of the profession. As situated within professional and pedagogical responsibilities framework, several studies have underscored ESL teachers' abilities to keep up-to-date with new trends and current educational research while also following domestic and international issues related to the education of L2 learners (Polat, 2010; Polat, \& Mahalingappa, 2013; Ramanathan \& Morgan, 2007). Furthermore, current research urges partnerships with outside resources, parents, and professional communities (Davison, 2006) while also promoting schooling that values just and equitable access to resources for all learners in inclusive environments (Reeves, 2004; Valdes, 2001).

\section{ELTE in Turkey}

In the last 30 years, several radical changes occurred in higher education policies in Turkey. A major change was in 1981 when a top-down oligarchic system of higher education, the Higher Education Council (HEC), (in Turkish: YOK) which held a notoriously high level of control over all financial, administrative, and educational functions of Turkish universities, was introduced (Coskun \& Daloglu, 2010). Upon the establishment of HEC, the Turkish education system began to experience a high level of influence by Western academics and/or Western-educated Turkish academics. Before this change, the debate about curricula was limited to the selection of courses and weight of subject areas; afterwards, the debate shifted towards the adoption of Western teacher education models (Kirkgoz, 2007).

Recently, HEC attempted to reform teacher education programs in Turkey (Buyukkantarcioglu, 2004; Kirkgoz, 2007), aiming to address numerous aspects of current curricular frameworks and improve the quality of teacher preparation to meet the changing demands of education in Turkey (Altan, 2006; Çakıroglu \& Çakıroglu, 2003). Upon this reform, subject-based teaching experiences and methodology courses, which were previously ignored, began to receive more emphasis. Consequently, foundation courses were redesigned and new courses like instructional planning, classroom management, and instructional technology were introduced (Buyukkantarcioglu, 2004; HEC, 2007). It is yet to be seen if HEC's control over these programs in terms of mandates and equitable distribution of resources has changed as a result of these reforms.

Currently, based on HEC mandates, the Turkish ELTE programs cover competencies related to language and linguistics, SLA theories, EFL methods, foundations of learning and teaching, practicum, instruction, and educational/pedagogical subjects. These competencies are further categorized into three HEC-mandated domains: (I) Language Teaching Subjects, (II) General Culture, and (III) Pedagogical Formation. Although HEC requires that all ELTE programs cover these domains, they allow the respective programs to construct or adopt elective courses that constitute around 25\% of the curriculum. Becoming an EFL teacher involves two paths in Turkey. The first one is through a four-year undergraduate degree in ELTE departments while in the second option candidates turn their English language and literature or cultural studies BA degrees into an EFL teacher licensure by fulfilling additional pedagogical formation requirements. The former, the subject of study in this paper, produces the majority of EFL teachers in Turkey.

Presently, entrance into an ELTE program is based on written English proficiency tests that cover reading, grammar, and vocabulary. In fact, possibly due to the traditional focus on grammar and grammar teaching in ELTE programs, ELF teachers in Turkey have been found to tend to focus on grammar instruction in their classrooms (Balci \& Cakir, 2012). As a result of the backwash effect (Hughes, 2003) and teaching-to-the-test preparation efforts, students lack proficiency in listening, writing and speaking skills (Kirkgoz, 2007; Sert, 2010), struggling severely in handling program coursework (Coskun \& Daloglu, 2010). Hence, it is no surprise that 
Mandates, needs, equitable resources, and current research in English language teacher education

some schools either require more preparation before admission into the program or increase the number of required general English classes in the first year of the program.

Studies that examined Turkish ELTE program candidates' beliefs reported many candidates believing that the HEC-led curricula neglect linguistic competence in favor of pedagogical competence (Coskun \& Daloglu, 2010). Some suggested that current ELTE programs paid little attention to candidates' language use and classroom interactions (Kirkgoz, 2007; Sert, 2010) while candidates in other studies agreed that they received insufficient teaching practice, and demanded more hands-on experiences and elective courses (Altan, 2006).

\section{Methods}

In addressing our research questions we draw on numeric data to provide evidence of statistical significance (Warner, 2008) while also providing interpretive qualitative data (Patton, 2002).

\subsection{Research questions}

This study involves a comparative analysis of ELTE curricula and qualitative accounts of program directors and teacher candidates in Turkey. Specifically, vis-à-vis current research in related fields:

1. What is the current situation of the ELTE programs in terms of curriculum strength and faculty resources?

2. How do the program directors envision the situation of their programs in terms of curriculum strength and faculty resources?

3. How do the teacher candidates envision the current situation of their programs in terms of curriculum strength and faculty resources?

\subsection{Participants and setting}

Participants came from 45 universities whose curricula were comparatively analyzed. Initially all 96 ELTE programs listed on the HEC website were included in the pool; however complete data were retrieved only from 45. Given the availability of resources and the quality of education offered in different regions in Turkey, we needed a sample that was somewhat representative of all ELTE programs. Thus, following the purposeful random sampling assumptions (Patton, 2002), eight ELTE program directors and 16 teacher candidates in their programs were interviewed. Namely, we randomly interviewed two teacher candidates and the program director from eight ELTE programs in categories of: private high-ranking, private low-ranking, public high-ranking, and public low-ranking school. We used programs' admission scores to determine their rank since Turkish programs are ranked according to their minimum admission scores.

Higher education work experience of the director participants ranged between 12 and 31 years (age range=39-57). Two program directors had received their PhD in the USA while all others received all of their higher education degrees in Turkey. The teacher candidates ( 4 from each school) had completed three and a half year undergraduate ELTE coursework and were enrolled in their last semester. Due to considerations related to confidentiality, ethics, and power relations, no data were collected from the programs with which the researchers were affiliated.

\subsection{Data sources}

Numeric and interview data were collected from 23 public and 22 private schools. Data included TESOL/NCATE standards, HEC requirements, ELTE curricula, semi-structured interviews, faculty areas of expertise, and programs' minimum English proficiency scores (Students are placed in ELTE programs based on their scores on a standard English test administered by the government annually). The professors' demographic 
Cepik, S. \& Polat, N.

data and ELTE curricula of the universities were either downloaded from university websites or directly obtained from the program directors while programs' minimum admission scores were tabulated from the HEC student selection and placement manual (2010). Since academics tend to follow multiple areas of research trajectories, for consistency purposes, we used the $\mathrm{PhD}$ concentration as the area of expertise.

Another primary data source was interview transcriptions. One set of semi-structured interview questions was constructed based on deductive codes (Miles \& Huberman, 1994) drawn from the teacher education program evaluation literature (Richards, 2007; Thomas \& Loadman, 2001) and inductive codes that emerged through the analysis of curricula (e. g., program description statements). These questions included: How do you see the current situation of ELTE programs in Turkey (curriculum/ faculty strengths, weaknesses, and opportunities)? Why? How do you see the current situation of your program curriculum in preparing competent teachers? Why? How do you think your program compares to other ELTE programs (added value)? What factors do you take into consideration while making decisions about which competencies, which courses, and how many credit hours? What competencies constitute the highlight of your program? Why a curriculum with this kind of focus (program's current curriculum)? Finally, the HEC requirements (2010) and the TESOL/NCATE standards manual (2010) were reviewed for within and between-program and setting comparisons.

\subsection{Data collection and analysis procedures}

First, all curricula were analyzed for commonly shared educational focus. Second, to determine the weighted coverage, credit hours for each category were calculated for each program. Third, the number of faculty members with a $\mathrm{PhD}$ in an area of expertise was calculated for each program. Due to uncontrollable variance in their backgrounds, instructors without a $\mathrm{PhD}$ were excluded. Fourth, these numbers and the school type (private/public) and rankings (high/low) were then entered into two Chi-square models in SPSS for descriptive and inferential computations. Fifth, to examine program directors' and teacher candidates' perceptions about the current situation of their programs, both groups were interviewed (Rubin \& Rubin, 2005). To reduce researcher interpretation bias, we individually (re)read each transcript and identified consistent themes related to specific competency areas, faculty qualifications, and so forth (Mishler, 1990). After comparing and identifying themes on which we both agreed, we adopted excerpts that contained consistent evaluative stances (Patton, 2002). Each interview, which took around 35 minutes, was conducted in English, recorded, transcribed, and returned to participants for corrections. In one case a transcription was modified per a program director's request. Lastly, the three HEC (2010) ELTE program requirements and the TESOL/NCATE manual (2010) were analyzed to determine the standards that constitute bases for ESL/EFL teacher education in Turkey and the USA.

\section{Findings}

\subsection{ELTE programs in Turkey}

To address research question one, two sets of comparative analyses were conducted: one on the curriculum and one on faculty expertise. The curriculum analyses results revealed eight commonly shared competency areas, including courses related to language skills, linguistics, methods, SLA, literature, practicum, foreign language, and educational core. Analyses of the weighted coverage of each category suggested three patterns: (1) although some variation seemed to exist in the weighted coverage of certain competencies across most schools, the curricula of majority of these universities were rather homogeneous both concerning the total credit-hour requirement and the credit-hour allocation for most competencies; and (2) a few universities (outliers) remarkably differed from the others both in the weighted coverage of several competency areas and the total number of credit-hours (Table 1). (3) Some significant associations were observed between school type and rank and the number of faculty members with different areas of expertise, which indicated that while HEC held all programs responsible for the coverage of the same pedagogical competencies, they failed to provide equitable resources across all programs. 
Mandates, needs, equitable resources, and current research in English language teacher education

Table 1

Credit-hour allocation of the eight competency areas across the 45 ELTE programs

\begin{tabular}{|c|c|c|c|c|c|c|c|c|c|c|}
\hline & Sta/Pri & Lang. cont & Lin & Met & SLA & Lit & Pra & FLE & $\mathrm{BEd}$ & $\mathrm{T}$ \\
\hline U1 & State & 33 & 6 & 36 & 3 & 8 & 8 & 6 & 24 & 124 \\
\hline U2 & State & 34 & 12 & 24 & 3 & 21 & 8 & 12 & 24 & 138 \\
\hline U3 & State & 33 & 6 & 39 & 3 & 9 & 8 & 6 & 28 & 132 \\
\hline U4 & State & 33 & 6 & 45 & 3 & 9 & 8 & 0 & 28 & 132 \\
\hline U5 & Private & 30 & 6 & 33 & 3 & 39 & 3 & 0 & 18 & 132 \\
\hline U6 & State & 33 & 6 & 45 & 3 & 9 & 8 & 7 & 22 & 133 \\
\hline U7 & State & 33 & 6 & 39 & 3 & 9 & 8 & 6 & 28 & 132 \\
\hline U8 & State & 33 & 6 & 39 & 3 & 9 & 6 & 9 & 30 & 135 \\
\hline U9 & State & 15 & 12 & 29 & 6 & 6 & 14 & 0 & 21 & 103 \\
\hline U10 & State & 33 & 6 & 39 & 3 & 9 & 8 & 6 & 28 & 132 \\
\hline U11 & State & 33 & 6 & 36 & 3 & 9 & 6 & 9 & 30 & 132 \\
\hline U12 & State & 33 & 6 & 39 & 3 & 9 & 8 & 6 & 28 & 132 \\
\hline U13 & Private & 33 & 6 & 39 & 3 & 9 & 8 & 6 & 28 & 132 \\
\hline U14 & Private & 33 & 6 & 39 & 3 & 9 & 8 & 6 & 28 & 132 \\
\hline U15 & Private & 33 & 6 & 39 & 3 & 9 & 8 & 6 & 28 & 132 \\
\hline U16 & Private & 33 & 6 & 42 & 3 & 9 & 6 & 6 & 27 & 132 \\
\hline U17 & State & 33 & 6 & 39 & 3 & 9 & 8 & 6 & 28 & 132 \\
\hline U18 & State & 33 & 6 & 39 & 3 & 9 & 8 & 6 & 28 & 132 \\
\hline U19 & State & 33 & 6 & 39 & 3 & 9 & 8 & 6 & 28 & 132 \\
\hline U20 & State & 33 & 6 & 39 & 3 & 9 & 8 & 6 & 28 & 132 \\
\hline U21 & Private & 3 & 22 & 33 & 7 & 9 & 10 & 0 & 20 & 104 \\
\hline U22 & Private & 30 & 6 & 31 & 3 & 9 & 8 & 9 & 23 & 119 \\
\hline $\mathrm{U} 23$ & State & 36 & 12 & 18 & 3 & 18 & 11 & 8 & 22 & 128 \\
\hline U24 & State & 33 & 6 & 39 & 3 & 9 & 8 & 6 & 28 & 132 \\
\hline $\mathrm{U} 25$ & State & 33 & 6 & 36 & 3 & 8 & 8 & 6 & 24 & 124 \\
\hline U26 & State & 33 & 6 & 39 & 3 & 9 & 8 & 6 & 28 & 132 \\
\hline U27 & State & 33 & 6 & 39 & 3 & 9 & 8 & 6 & 28 & 132 \\
\hline U28 & Private & 33 & 6 & 42 & 3 & 9 & 6 & 6 & 27 & 132 \\
\hline U29 & State & 36 & 12 & 18 & 3 & 18 & 11 & 8 & 22 & 128 \\
\hline U30 & Private & 33 & 6 & 42 & 3 & 9 & 6 & 6 & 27 & 132 \\
\hline U31 & Private & 33 & 6 & 39 & 3 & 9 & 8 & 6 & 28 & 132 \\
\hline U32 & State & 33 & 6 & 39 & 3 & 9 & 8 & 6 & 28 & 132 \\
\hline U33 & Private & 33 & 6 & 33 & 3 & 9 & 8 & 6 & 30 & 128 \\
\hline U34 & Private & 33 & 12 & 36 & 3 & 9 & 8 & 6 & 28 & 132 \\
\hline U35 & Private & 36 & 12 & 31 & 3 & 9 & 8 & 6 & 27 & 132 \\
\hline U36 & Private & 33 & 6 & 39 & 3 & 12 & 8 & 8 & 24 & 125 \\
\hline U37 & Private & 36 & 6 & 39 & 3 & 9 & 8 & 9 & 22 & 132 \\
\hline U38 & Private & 33 & 12 & 33 & 3 & 9 & 8 & 6 & 28 & 132 \\
\hline U39 & State & 30 & 6 & 39 & 3 & 9 & 11 & 6 & 28 & 132 \\
\hline U40 & Private & 33 & 6 & 36 & 3 & 9 & 8 & 9 & 28 & 132 \\
\hline U41 & Private & 36 & 6 & 36 & 3 & 9 & 6 & 6 & 30 & 132 \\
\hline U42 & Private & 33 & 6 & 31 & 3 & 9 & 8 & 9 & 24 & 123 \\
\hline U43 & Private & 36 & 12 & 27 & 3 & 12 & 6 & 9 & 27 & 132 \\
\hline U44 & Private & 30 & 6 & 36 & 7 & 9 & 8 & 8 & 28 & 132 \\
\hline U45 & Private & 33 & 6 & 36 & 3 & 8 & 6 & 6 & 24 & 122 \\
\hline
\end{tabular}

Note. Sta: State; Pri: Private; Lan cont: Language content; Lin: Linguistics; Met: Methods; Lit: Literature; FL: Foreign language; BEd: Basic education; T: Total

Descriptive statistics (Table 1) suggested a remarkably homogenous distribution of credit-hours allocated for the eight competencies across the 45 programs. Since the weighted credit-hour units consisted of uneven categorical data, chi-square, a non-parametric test was used to examine the associations between the school type and rank and the coverage of different competencies. Results indicated that, of the eight competencies, the relationship between the number of weighted credit-hours and school type (private and public) was significant only regarding one area: practicum, $\chi 2(1,44)=5.78, p<.05$. Public universities were more likely to offer higher number of practicum hours than private ones. Similarly, the only statistically significant relationship between 
school rank and the weighted credit hour-allocation was about basic education courses $\left[\chi^{2}(1,44)=3.93, p<.05\right]$, with a higher probability that low-ranking schools would offer more basic education courses.

Another chi-square test was run to examine possible relationships between school type and rank and the distribution of faculty across competency areas as well as the total number of $\mathrm{PhD}$ faculty. The lowest admission score was 329 and the highest was 552. Programs at or above the average (466) were coded as high-ranking and those beneath as low-ranking. Results suggested that the total number of faculty varied between 2 and 14 across all programs. Chi-square analyses revealed a significant association between school type and the number of faculty with a PhD in foreign language education (FLE) $\left[\chi^{2}(1,44)=4.28, p<.05\right]$, suggesting a higher likelihood that public schools would have higher number of $\mathrm{PhD}$ faculty in this area than private schools. While no other significant relationships were found between school type and the number of PhD faculty in other areas, results indicated significant associations between school rank and the number of $\mathrm{PhD}$ faculty with expertise in: FLE, $\chi 2$ $(1,44)=6.71, p<.01$, applied linguistics, $\chi 2(1,44)=5.86, p<.05$, and total number of $\mathrm{PhD}$ faculty in a program, $\chi^{2}(1,44)=10.90, p<.00$. Namely, Table 2 shows that high-ranking schools were more likely to have a comparative advantage over the low-ranking ones in all of these three areas. Finally, despite having sampled almost half of the Turkish ELTE programs, the sample size is not big enough to examine the interaction of school type and rank. Nonetheless, descriptive statistics (Table 2) demonstrates that high-ranking public schools had the highest total number of faculty members $(\mathrm{M}=8.5)$ and the highest number of $\mathrm{PhD}$ faculty with expertise in linguistics and FLE.

\subsection{Program directors' perceptions}

Four consistent themes emerged in program directors interviews. While discussing pre-service teacher competency as represented by current 'knowledge base' (Richards, 2009) of their curricula, particularly their strengths, weaknesses, and curricular focus, the directors consistently underscored the role of (1) teacher candidates' language needs, (2) faculty background, (3) HEC requirements, and (4) the Public Personnel Selection Examination (PPSE) (in Turkish: KPSS). The interview data suggested that the program directors consistently argued on behalf of their programs; they reported to believe that their programs are rather strong in serving the teacher candidates yet, admitted that many program instructors teach courses outside their area of expertise. For example, Lale; a program director at a high-ranking public university, relayed:

ELT programs in Turkey don't have many weaknesses. I think our programs are rather rich from theoretical perspective. One BIG (emphatic) weakness is that there is a lack of teaching staff who are experts in courses they teach.

In addition, director participants consistently reported to perceive their programs as having strong academic foundation that informs teacher practices (Bartels, 2005); however they seemed to believe that many teacher candidates may not benefit from their programs well enough simply because they are not proficient in English. In fact, Salih; from a high-ranking private university, commented that the students are admitted into ELTE programs when "they pass a multiple-choice test on grammar and reading. So, their listening, writing, and speaking skills are bad". He added that they "offer good education, but students may not learn it because they do not speak English well".

In addressing questions about factors to be considered while making decisions about competencies and their weighted coverage in the curriculum, director participants got rather emotional. Consistent with other participants' comments, Cenk, from a low-ranking public university, underscored that their professional expertise and understanding of students' needs did not matter much in the current system because he argued "The needs of learners must be taken into consideration but the frame of our curriculum is not designed by us. Most of it is decided by HEC. But who is HEC? ELT professionals?" This result is interesting because, as studied in the Turkish context too, perceptions about the self-autonomy and power administrators' and instructors' have over the curriculum may have an impact on their motivation (Erkaya, 2013). Relatedly, director participants also 
Mandates, needs, equitable resources, and current research in English language teacher education

seemed to believe that the strength of ELTE programs did not really matter because candidates who receive high scores on Math and social science test (PPSE) get the jobs- not necessarily those who have attained the highest levels of professional competency. Another participant, from a low-ranking private university, Zeynep, stated that in current system "it isn't important how great a program is. There is a contradiction between ELT curriculums and the expectations of Education Ministry". Thus, she questioned "the value of all of our courses since only successful students on KPSS (meaning PPSE) can become teachers in State schools".

Table 2

Distribution of faculty by area of expertise across public versus private and high versus low-ranking universities

\begin{tabular}{|c|c|c|c|c|c|c|c|c|c|c|}
\hline & Type & Rank & Lin & $\mathrm{ALi}$ & FLE & SLA & Lit & $\mathrm{CSt}$ & Ged & TNF \\
\hline U1 & 1 & 1 & 0 & 1 & 5 & 0 & 1 & 0 & 0 & 7 \\
\hline U2 & 1 & 1 & 6 & 1 & 3 & 1 & 1 & 0 & 3 & 9 \\
\hline U3 & 1 & 1 & 1 & 0 & 4 & 0 & 0 & 0 & 0 & 5 \\
\hline U4 & 1 & 1 & 0 & 0 & 4 & 0 & 2 & 0 & 1 & 7 \\
\hline U5 & 2 & 1 & 0 & 0 & 0 & 0 & 4 & 1 & 1 & 6 \\
\hline U6 & 1 & 1 & 1 & 1 & 7 & 0 & 2 & 0 & 3 & 14 \\
\hline U7 & 1 & 2 & 0 & 0 & 2 & 0 & 1 & 0 & 1 & 4 \\
\hline U8 & 1 & 1 & 0 & 0 & 3 & 0 & 1 & 0 & 1 & 5 \\
\hline U9 & 1 & 1 & 3 & 2 & 2 & 2 & 1 & 1 & 0 & 11 \\
\hline U10 & 1 & 2 & 0 & 0 & 5 & 0 & 0 & 0 & 2 & 7 \\
\hline U11 & 1 & 2 & 1 & 0 & 2 & 0 & 0 & 1 & 1 & 3 \\
\hline U12 & 1 & 2 & 0 & 0 & 1 & 0 & 0 & 0 & 1 & 2 \\
\hline U13 & 2 & 1 & 0 & 0 & 1 & 0 & 1 & 0 & 2 & 4 \\
\hline U14 & 2 & 2 & 0 & 0 & 4 & 0 & 0 & 0 & 1 & 5 \\
\hline U15 & 2 & 1 & 2 & 0 & 1 & 0 & 1 & 0 & 0 & 4 \\
\hline U16 & 2 & 2 & 0 & 0 & 3 & 0 & 1 & 0 & 1 & 5 \\
\hline U17 & 1 & 2 & 0 & 0 & 2 & 0 & 1 & 0 & 1 & 4 \\
\hline U18 & 1 & 1 & 1 & 2 & 5 & 0 & 3 & 0 & 1 & 12 \\
\hline U19 & 1 & 2 & 0 & 0 & 1 & 0 & 1 & 0 & 0 & 2 \\
\hline U20 & 1 & 2 & 2 & 0 & 3 & 0 & 1 & 0 & 0 & 4 \\
\hline U21 & 2 & 1 & 1 & 1 & 3 & 0 & 0 & 0 & 0 & 5 \\
\hline U22 & 2 & 1 & 0 & 0 & 2 & 0 & 0 & 1 & 1 & 4 \\
\hline $\mathrm{U} 23$ & 1 & 2 & 0 & 0 & 1 & 0 & 1 & 0 & 1 & 3 \\
\hline U24 & 1 & 2 & 0 & 0 & 3 & 0 & 0 & 0 & 0 & 3 \\
\hline $\mathrm{U} 25$ & 1 & 2 & 0 & 1 & 2 & 0 & 2 & 0 & 1 & 6 \\
\hline U26 & 1 & 2 & 0 & 0 & 1 & 0 & 1 & 0 & 1 & 3 \\
\hline U27 & 1 & 2 & 0 & 0 & 2 & 0 & 0 & 0 & 1 & 3 \\
\hline U28 & 2 & 2 & 3 & 0 & 0 & 0 & 1 & 0 & 1 & 5 \\
\hline U29 & 1 & 1 & 1 & 0 & 2 & 0 & 1 & 2 & 1 & 7 \\
\hline U30 & 2 & 1 & 0 & 1 & 2 & 0 & 2 & 0 & 0 & 5 \\
\hline U31 & 2 & 2 & 2 & 0 & 1 & 0 & 1 & 0 & 0 & 4 \\
\hline U32 & 1 & 2 & 0 & 0 & 1 & 0 & 0 & 0 & 1 & 2 \\
\hline U33 & 2 & 2 & 0 & 0 & 1 & 0 & 0 & 0 & 1 & 2 \\
\hline U34 & 2 & 2 & 0 & 0 & 1 & 0 & 1 & 0 & 2 & 4 \\
\hline U35 & 2 & 2 & 3 & 0 & 0 & 0 & 1 & 0 & 1 & 5 \\
\hline U36 & 2 & 2 & 1 & 0 & 2 & 0 & 1 & 2 & 1 & 4 \\
\hline U37 & 2 & 2 & 2 & 1 & 2 & 0 & 2 & 0 & 0 & 5 \\
\hline U38 & 2 & 2 & 2 & 0 & 1 & 0 & 1 & 0 & 0 & 7 \\
\hline U39 & 1 & 2 & 2 & 0 & 1 & 0 & 1 & 0 & 0 & 4 \\
\hline U40 & 2 & 1 & 1 & 1 & 3 & 0 & 0 & 0 & 0 & 4 \\
\hline U41 & 2 & 1 & 0 & 0 & 2 & 0 & 0 & 1 & 1 & 5 \\
\hline U42 & 2 & 1 & 0 & 0 & 3 & 0 & 1 & 0 & 1 & 5 \\
\hline U43 & 2 & 1 & 0 & 0 & 1 & 0 & 1 & 0 & 2 & 4 \\
\hline U44 & 2 & 1 & 0 & 0 & 3 & 0 & 0 & 0 & 1 & 6 \\
\hline $\mathrm{U} 45$ & 2 & 1 & 2 & 0 & 1 & 0 & 1 & 0 & 0 & 4 \\
\hline
\end{tabular}

Note. Type: 1= public, $2=$ private; Rank: 1= high, 2= low; Lin.: linguistics; ALin.: applied linguistics; FLE.: foreign language education; SLA.: second language acquisition,; Lit.: literature; CSt.: cultural studies; Ged.: general education; TNF.: total number of faculty 


\subsection{Teacher candidates' perceptions}

The interview data suggested some discrepancies in the perceptions of teacher candidates; however four emergent themes seemed to be shared by the overwhelming majority. Quite interestingly though, while two of these themes- (1) teacher candidates' language needs and (2) faculty expertise- appeared to match the themes also shared by the programs directors, two of them- (3) heavy theory-orientation, (4) lack of facilitating practicum- were unique to the teacher candidates.

Teacher candidates' perceptions sounded rather similar to those of program directors' while discussing how their language needs were met in these programs. Nonetheless, unlike the program directors, these candidates seemed to link their lack of L2 proficiency to the lack of language foundation-based discipline (Larsen-Freeman, 2003) and the lack of native-speaker instructors, building on the 'native-speaker fallacy' in L2 teaching (Canagarajah, 1999). For example, Banu; a candidate at a low-ranking private school, said:

There is just one native-speaker teacher (professor) in our program. For years we listened to Turkish teachers and our language skills do not get better. I mean most speak with heavy Turkish accent. We don't get native-speakers teach us English.

Unlike the program directors, teacher candidates described their programs to be too theoretical and lack sufficient practical applications, voicing a concern shared by many about teacher education around the world (Darling-Hammond, 2005). Ertugrul; at a high-ranking public, school shared a concern that "programs have enough theory not practice". He continued, "We learnt ABOUT (emphatic) methods of teaching writing, reading, speaking but we didn't really teach and improve. Also, our professors always said no grammar translation method but at practicum schools everyone is teaching grammar translation". Similarly, Asli; at a high-ranking private school, portrayed her programs as short of effective practicum experiences that complement their education (Burns \& Richards, 2009), questioning both the credit-hour allocation and the competency of their cooperating teachers who often play a critical role (Velez-Rendon, 2006). She insisted that "one year of practicum isn't enough" and that "the supervision isn't very strict". She persistently underscored the mismatch between their university education and what they observe at practicum schools when she said: "Practicum teachers do all things our professors tell us we should not do".

\section{Discussion}

\subsection{The current situation}

Taken together, our results suggest that (1) despite a few outliers, the majority of ELTE programs offer a homogeneous curriculum with a markedly similar number of credit-hour allocation for each competency; (2) several significant associations exist between school's rank and the number of faculty with expertise in FLE, applied linguistics, and the total number of $\mathrm{PhD}$ faculty; (3) it is more likely that public schools would have higher number of PhDs with FLE degrees than private schools, with a noticeable comparative advantage for high-ranking public schools in all three areas; (4) some perceptual matches and mismatches (Kumaravadivelu, 2006) exist between the program directors and teacher candidates regarding the ELTE program curricula; and (5) compared to current research in the field, these program seem to lack several essential competencies.

These results corroborate previous research that HEC still strictly controls higher education in Turkey (Kirkgoz, 2007), revealing that all 45 programs offered courses related to eight competency areas; yet the number of credit-hours allocated for some competencies varied across high and-low and private and-public schools. Notwithstanding a few exceptions (Univ9 and Univ21), the total number of credit-hours was strikingly similar for many areas. Regarding school type and rank, our analyses yielded rather interesting findings. For example, public universities seemed to offer significantly higher number of practicum courses and higher contextualized 'apprenticeship' opportunities (Darling-Hammond \& Branson, 2005) than the private ones despite 
Mandates, needs, equitable resources, and current research in English language teacher education

the fact that the faculty areas of expertise at both types of schools were rather similar. Nonetheless, differences in the number of faculty in certain areas seem to be quite substantial between the low versus high-ranking schools, with a higher probability level that high-ranking universities would have higher numbers of PhD faculty with expertise in FLE and applied linguistics. These results suggest that HEC does not seem to provide all ELTE programs with the same resources; yet they demand that all programs offer the same quality of education to their student.

\subsection{Perceptions of teacher candidates and program directors}

Results revealed some level of agreement between the two groups, indicating that both the service providers and their clients were aware of some of the major programmatic strengths and weaknesses. Two of the four themes that were shared by the overwhelming majority of program directors, were also shared by the majority of teacher candidates. Both groups underscored that teacher candidates join the ELTE programs with inadequate English proficiency, which corroborate the findings of previous research (Coskun \& Daloglu, 2010; Kirkgoz, 2007; Sert, 2010). Nonetheless, program directors blamed the grammar-based State admission test whereas teacher candidates blamed their programs for not effectively using the estimated 33 credits of language-study to help them improve their English while in the program. This mismatch in expectations is rather striking because it seems like teacher educators expect candidates to have near-native proficiency in English before joining the program whereas the candidates consider these programs both as language learning and teacher preparation programs. Interestingly, the programs directors seem to consider over $20 \%$ of the credit-hour allocation for the English studies as inadequate while the teacher candidates question the effective use of these hours rather than the quantity. In justifying their perceptions about ineffectiveness, for example, the teacher candidates consistently complained about the lack of native-speaker instructors (Canagarajah, 1999) and the use of accented (Turkish) English.

In addition, both groups reported lack of expert faculty as a weakness. During interviews, many candidates argued that some instructors were assigned to teach courses out of their areas. Taken together with our analyses above, these findings probably resonate more with the situation of the low-ranking schools, most of which are located in southeast and eastern Anatolia. On the other hand, program directors and teacher candidates seemed to hold different perceptions about other programmatic strengths and weaknesses. For example, the program directors acknowledged the mismatch between their curricula and the needs of students; however they unanimously held responsible HEC's rigid control over their decision-making, a notion frequently voiced in research (Coskun \& Daloglu, 2010) even after some of the latest educational reforms (Çakıroglu \& Çakıroglu, 2003; Kirkgoz, 2007).

Finally, sometimes program components viewed as strengths by a particular group would be presented as weaknesses by the other. For example, it was interesting how the program directors considered the theoretical focus of their programs when they discussed their strengths (Lale) whereas the teacher candidates mentioned it as a weakness (Ertugrul). Relatedly, these teacher candidates, regardless of their program type and rank, identified inadequate and ineffective practicum experience as an important weakness (Burns \& Richards, 2009), underscoring numerous shortcomings related to the number of hours, site selection, effective supervision, and competency of cooperating teachers (Velez-Rendon, 2006). Indeed, despite HEC's mandate to follow the Bologna quality assurance standards (European Association for Quality Assurance in Higher Education, 2005), current ELTE programs in Turkey continue to offer courses with occasional practicum blocks rather than integrated cycles (Kirkgoz, 2007).

\section{Conclusions and implications}

This study potentially offers several implications that may be central both to the development of ELTE programs and related L2 teacher education policies around the world. Indeed, national standardization efforts in teacher education exist virtually everywhere across the globe (For a review see, Darling-Hammond \& Brenson, 
Cepik, S. \& Polat, N.

2005). In light of our analyses of the curriculum and the TESOL/NCATE standards, ELTE programs in Turkey seem to lack: (1) a conceptual framework that is comprehensive, current, and consistent with SLA and L2 teacher education research (Bartels, 2005; Borg, 2006; Burns \& Richards, 2009; Ellis, 2012; Nation \& Macalister, 2010; Tredick, 2004); (2) a curriculum that is designed by the faculty to meet the specific needs of teacher candidates; (3) a focus on competency in language and SLA (Gass \& Selinker, 2008; VanPatten \& Williams, 2007) and culture (Gay, 2010; Johnson, 2009) domains; (4) content on instructional methods that meet the needs of teacher candidates, as evident in the critical accounts of the directors and the teacher candidates (Larsen-Freeman, 2003; Kumaravadivelu, 2006; Richards \& Rodgers, 2001); and, (5) content on L2 testing (Fulcher \& Davidson, 2006; Hughes, 2003), which is markedly ignored. Most importantly (6), however, if these programs are to be held accountable to deliver the same quality of instruction and practicum experiences, HEC must follow a more equitable and just approach in the appointments of faculty with relevant background in the field.

In the Turkish context, some form of HEC's control over these programs may be justifiable for standardization and accreditation purposes. Yet, in its current form, as evidenced in the qualitative data, HEC's excessive control seems to undermine the effectiveness of these programs by demoralizing and disempowering the program faculty and enforcing statewide curricular mandates without providing equal faculty resources for all programs. In addition, in light of our triangulated data sources, including our interpretation of the qualitative accounts and the inferences of the quantitative results, several systematic steps that should involve dramatic changes both in the ELTE and related higher education policies, are necessary to ensure programmatic improvement and effectiveness. First, the language testing system for admission should be replaced with a more rigorous, valid, reliable, and comprehensive measure (Brown, 2004; Hughes, 2003), that assesses candidates' overall proficiency. Second, similar to practices in the USA or UK, HEC should either allow the universities to conduct their own faculty appointments or ensure equal distribution of high quality expertise across all programs. Third, effective practicum experiences that provide adequate number of hours in relevant school sites accompanied with effective supervision and up-to-date cooperating teachers are also warranted. Fourth, an EFL teacher PRAXIS that is aligned with ELTE and measures candidates' knowledge, skills, and disposition should be replaced with the current general knowledge evaluation system. Fifth, to keep teachers up-to-date with current innovations in L2 education, a national standards-based system that would provide systematic in-service professional development activities should also be implemented. Finally, a need for independent ELTE accreditation agencies is warranted for further improvement of these programs.

\section{References:}

Altan, M. Z. (2006). Preparation of Foreign language teachers in Turkey: A challenge for the 21st century. Dil Dergisi, 134, 49-54.

Andrews, L. (2001). Linguistics for L2 teachers. Mahwah, NJ: Erlbaum.

Balci, O. \& Cakir, A. (2012). Teaching vocabulary through collocations in EFL Classes: The case of Turkey. International Journal of Research Studies in Language Learning, 1, 21-32. http://dx.doi.org/10.5861/ijrsll.2012.v1i1.31

Bartels, N. (Ed). (2005). Applied linguistics and language teacher education. New York: Springer. http://dx.doi.org/10.1007/1-4020-2954-3

Borg, S. (2006). Teacher cognition and language education. London: Continuum.

Brown, H. D. (2004). Language assessment: Principles and classroom practices. New York: Longman.

Burns, A., \& Richards, J. C. (2009). The Cambridge guide to second language teacher education. New York: Cambridge University Press.

Buyukkantarcioglu, N. (2004). A sociolinguistic analysis of the present dimensions of English as a foreign language in Turkey. International Journal of the Sociology of Language, 165, 33-58.

Çakıroglu, E., \& Çakıroglu, J. (2003). Reflections on teacher education in Turkey. European Journal of Teacher Education, 26, 253-264. http://dx.doi.org/10.1080/0261976032000088774 
Mandates, needs, equitable resources, and current research in English language teacher education

Canagarajah, A. S. (1999). Interrogating the "native speaker fallacy": Non-linguistic roots, non-pedagogical results. In G. Braine (Ed), Non-native educators in English language teaching (pp. 77-92). Mahwah, New Jersey: Erlbaum.

Coskun, A., \& Daloglu, A. (2010). Evaluating an English language teacher education program through Peacock's model. Australian Journal of Teacher Education, 35, 24-42. http://dx.doi.org/10.14221/ajte.2010v35n6.2

Darling-Hammond, L., \& Branson, J. (Ed). (2005). Preparing teachers for a changing world: What teachers should learn and be able to do. San Francisco, CA: Jossey-Bass Publishers.

Davison, C. (2006). Collaboration between ESL and content teachers: How do we know when we are doing it right? International Journal of Bilingualism and Bilingual Education, 9, 1-20. http://dx.doi.org/10.2167/beb339.0

Dörnyei, Z. (2005). The psychology of the language learner: Individual differences in second language acquisition. Mahwah, NJ: Erlbaum.

Ellis, R. (2012). Language teaching research and language pedagogy. Boston: Wiley-Blackwell. http://dx.doi.org/10.1002/9781118271643

Erkaya, O.R. (2013). Factors that motivate Turkish EFL teachers. International Journal of Research Studies in Language Learning, 1, 49-65.

European Association for Quality Assurance in Higher Education. (2005). Standards and guidelines for quality assurance in the European higher education. Retrieved from http://www.ond.vlaanderen.be/hogeronderwijs/bologna/documents/Standards-and-Guidelines-for-QA.p df

Fulcher, G., \& Davidson, F. (2006). Language testing and assessment: An advanced resource book. New York: Routledge. http://dx.doi.org/10.4324/9780203449066

Gass, S. M., \& Selinker, L. (2008). Second language acquisition: An introductory course. New York: Routledge.

Gay, G. (2010). Culturally responsive teaching: Theory, research, and practice. New York: Teachers College Press.

HEC. (2000). Minimum requirements for applying to become associate professor [in Turkish]. Retrieved from http://www.yok.gov.tr/uakpdfs/tablo1.pdf

HEC. (2010). Student placement scores for undergraduate degree programs. Retrieved from http://www.yok.gov.tr/content/view/795/194/lang,tr/

Hinkel, E., (2005). Handbook of research in second language teaching and learning. Mahwah, NJ: Lawrence Erlbaum.

Horwitz, E. K. (2013). Becoming a language teacher: A practical guide to second language learning and teaching. Boston, MA: Pearson.

Hughes, A. (2003). Testing for language teachers. Oxford: Oxford University Press.

Johnson, K. E. (2009). Second language teacher education: A sociocultural perspective. New York: Routledge.

Kachru, B. B., Kachru, Y., \& Nelson, C. L. (Eds). (2006). The handbook of world Englishes. Oxford: Blackwell.

Kelly, M., Grenfell, M., Allan, R., Criza, C., \& McEvoy, W. (2004). European profile for language teacher education: A frame of reference. A report to the European commission directorate general for education and culture. Southampton, UK: University of Southampton.

Kirkgoz, Y. (2007). English language teaching in Turkey: Policy changes and their implementations. RELC Journal, 38, 216-228. http://dx.doi.org/10.1177/0033688207079696

Kumaravadivelu, B. (2006). TESOL methods: Changing tracks, challenging trends. TESOL Quarterly, 40, 59-81. http://dx.doi.org/10.2307/40264511

Larsen-Freeman, D. (2003). Teaching language: From grammar to grammaring. Boston: Thompson-Heinle.

Miles, M. B., \& Huberman, A. M. (1994). Qualitative data analysis. London: Sage.

Mishler, E. G. (1990). Validation in inquiry-guided research: The role of exemplars in narrative studies. Harvard Educational Review, 60, 415-442.

Nation, I.S.P., \& Macalister, J. (2010). Language curriculum design. New York, NY: Taylor and Francis.

Patton, M. Q. (2002). Qualitative research and evaluation methods. Thousand Oaks, CA: Sage. 
Cepik, S. \& Polat, N.

Polat, N. (2010). A comparative analysis of pre-and in-service teacher beliefs about readiness and self-competency: Revisiting teacher education for ELLs. System, 38, 228-244. http://dx.doi.org/10.1016/j.system.2010.03.004

Polat, N., \& Mahalingappa, L. (2013). Examining service and gender effects on teacher beliefs about ELLs in content area classes: A case for inclusion, responsibility and instructional support. Teaching Education, 24, 58-83. http://dx.doi.org/10.1080/10476210.2012.713930

Ramanathan, V., \& Morgan, B. (2007). TESOL and policy enactments: Perspectives from practice. Introduction to the special issue on language policy. TESOL Quarterly, 41, 447-463.

Reeves, J. (2004). 'Like everybody else': Equalizing educational opportunity for English language learners. TESOL Quarterly, 38, 43-66. http://dx.doi.org/10.2307/3588258

Richards, J. C. (2007). Curriculum development in language teaching. Cambridge: Cambridge University Press.

Richards, J. C. (2008). Second language teacher education today. RELC Journal, 39, 158-177. http://dx.doi.org/10.1177/0033688208092182

Richards, J., \& Rodgers, T. (2001). Approaches and methods in language teaching. Cambridge: Cambridge University Press. http://dx.doi.org/10.1017/CBO9780511667305

Rubin, H. J., \& Rubin, I. S. (2005). Qualitative interviewing: The art of hearing data. Thousand Oaks, CA: Sage.

Sert, O. (2010). A proposal for a CA-integrated English language teacher education program in Turkey. The Asian EFL Journal Quarterly, 12, 62-97.

TESOL/NCATE Program Standards. (2010). Retrieved from http://www.tesol.org/s tesol/bin.asp?CID=219\&DID=13040\&DOC=FILE.PDF

Thomas, A. M., \& Loadman, W. E. (2001). Evaluating teacher education programs using a national survey. The Journal of Educational Research, 94, 195-206. http://dx.doi.org/10.1080/00220670109598753

Tredick, D. J. (2004). Second language teacher education: International perspectives. New York: Routledge.

Valdes, G. (2001). Learning and not learning English: Latino students in American schools. New York: Teachers College Press.

VanPatten, B., \& Williams, J. (2007). Theories in second language acquisition: An introduction. Mahwah, NJ: Erlbaum.

Velez-Rendon, G. (2006). From student to teacher: A successful transition. Foreign Language Annals, 39, 320-333. http://dx.doi.org/10.1111/j.1944-9720.2006.tb02269.x

Warner, R. M. (2008). Applied statistics: From bivariate to multivariate techniques. Los Angeles, CA: Sage. 